\title{
Descriptive statistics and correlation analysis of agronomic traits in a maize recombinant inbred line population
}

\author{
H.M. Zhang ${ }^{1,4}$, G.Q. Hui ${ }^{1,4}$, Q. Luo ${ }^{1,4}$, Y. Sun ${ }^{3,4}$ and X.H. Liu ${ }^{2}$ \\ ${ }^{1}$ Maize Research Institute, Shanxi Academy of Agricultural Sciences, \\ Xinzhou City, China \\ ${ }^{2}$ College of Life Science, China West Normal University, Nanchong City, China \\ ${ }^{3}$ Biotechnology Research Center, \\ Shanxi Academy of Agricultural Sciences, Taiyuan City, Shanxi, China \\ ${ }^{4}$ Key Laboratory of Crop Gene Resources and Germplasm Enhancement on \\ Loess Plateau, Ministry of Agriculture, China \\ Corresponding author: X.H. Liu \\ E-mail: liuxiaohong0817@aliyun.com
}

Genet. Mol. Res. 13 (1): 457-461 (2014)

Received August 18, 2013

Accepted October 22, 2013

Published January 21, 2014

DOI http://dx.doi.org/10.4238/2014.January.21.14

\begin{abstract}
Maize (Zea mays L.) is one of the most important crops in the world. In this study, 13 agronomic traits of a recombinant inbred line population that was derived from the cross between Mo17 and Huangzao4 were investigated in maize: ear diameter, ear length, ear axis diameter, ear weight, plant height, ear height, days to pollen shed (DPS), days to silking (DS), the interval between DPS and DS, 100-kernel weight, kernel test weight, ear kernel weight, and kernel rate. Furthermore, the descriptive statistics and correlation analysis of the 13 traits were performed using the SPSS 11.5 software. The results providing the phenotypic data here are needed for the quantitative trait locus mapping of these agronomic traits.
\end{abstract}

Key words: Maize (Zea mays L.); Agronomic traits; Descriptive statistics; Correlation analysis 


\section{INTRODUCTION}

Quantitative trait locus (QTL) mapping depends on a segregating population. Although there are many types of maize segregating populations, $\mathrm{F}_{2}$ and backcross are the most widely applied populations in maize (Zea mays L.) breeding. The 2 populations are not timeconsuming and have a low cost. However, in QTL mapping no continuous plants are used for phenotypic investigations and DNA extraction; thus, the 2 population types have the deficiency named temporality (Pilet et al., 2001). Comparatively, recombinant inbred line (RIL) populations are immortal and can be utilized in different regions and times because of their homogeneous individuals. Of course, these populations are associated with longer time commitments and higher costs for population construction than $\mathrm{F}_{2}$ and backcross populations (Wan et al., 2008). Currently, the studies using an RIL as a mapping population are focused on a few crops, including rice (Wan et al., 2006), soybean (Fu et al., 2006), and wheat (Ma et al., 2007). Only limited reports were found in maize in the literature (Bouchez et al., 2002; Ordas et al., 2008), especially in China (Ding et al., 2008).

Maize is one of the most important crops throughout the world. The studies on QTL mapping of maize agronomic traits have been reported frequently and include traits that are related to plant phenotype (Ribaut et al., 1997), yield (Guo et al., 2008), and flower period (Liu et al., 2010). Nevertheless, the number, location, and genetic effects of QTL for some traits demonstrate differences in different experiments. These results are influenced to some extent by different mapping parents, population types, and genetic maps.

Therefore, an RIL population that was derived from the 2 elite inbred lines Mo17 and Huangzao4 was used as experimental material, and 13 important agronomic traits were investigated and analyzed. The objective of this study was to provide phenotypic data for further QTL mapping of these traits.

\section{MATERIAL AND METHODS}

\section{Plant materials}

The experimental materials included parental lines Mo17 and Huangzao4 and an RIL population consisting of 221 RILs. Mo17 and Huangzao4 belong to Lancaster (USA) and Tangsipingtou (China) heterotic groups, respectively; the RIL population was derived from the cross between Mo17 and Huangzao4.

\section{Experimental methods}

All 223 lines were sown in a completely randomized design with 6 replicates at the experiment field (Shanxi Academy of Agricultural Sciences, Xinzhou City, Shanxi Province, China) that had single-row planting for each replicate, 20 plants per row, $67 \mathrm{~cm}$ as the row interval, and $25 \mathrm{~cm}$ as the plant interval within a row. During florescence, the middle 10 plants of every replicate of each line were individually investigated for the 13 traits: ear diameter (ED), ear length, ear axis diameter (EAD), ear weight, plant height, ear height, days to pollen shed (DPS), days to silking (DS), the interval between DPS and DS (IPS), 100-kernel weight $(\mathrm{KW})$, kernel test weight, ear kernel weight, and kernel rate. In total, 60 plants per line were 
used to compute the mean. Based on the statistical means, descriptive statistics and relation analysis were performed using the SPSS11.5 software (www.spss.com).

\section{RESULTS AND DISCUSSION}

\section{Descriptive statistics for parents and population}

For the parents, the average values from Mo17 were higher than those from Huangzao4 for all 13 traits except KW, ED, and EAD (Table 1). With regard to the population, the results of phenotypic statistics, including mean, skewness, kurtosis, minimum, maximum, and coefficient of variation $(\mathrm{CoV})$, are shown in Table 2 . The 5 parameters including mean, skewness, kurtosis, minimum, and maximum could not be compared between the 13 traits. However, the CoV can be used to reflect the variation extent of different RILs in the population. The CoV value of IPS was the highest (up to $36.38 \%$ ), followed by KW (33.84\%); the lowest was DS $(3.25 \%)$.

From these statistical values, it was concluded that the 13 agronomic traits were quantitative and were controlled by multiple genes.

Table 1. Descriptive statistics for parental lines Mo17 and Huangzao4.

\begin{tabular}{|c|c|c|c|c|c|c|c|c|c|c|c|c|c|}
\hline Genotypes & $\begin{array}{c}\mathrm{KW} \\
(\mathrm{g})\end{array}$ & $\begin{array}{l}\text { KR } \\
(\%)\end{array}$ & $\begin{array}{c}\text { KTW } \\
\text { (g) }\end{array}$ & $\begin{array}{c}\text { EGW } \\
(\mathrm{g} / \mathrm{L})\end{array}$ & $\begin{array}{l}\text { DPS) } \\
\text { (days }\end{array}$ & $\begin{array}{c}\text { DS } \\
\text { (days) }\end{array}$ & $\begin{array}{l}\text { IPS } \\
\text { (days) }\end{array}$ & $\begin{array}{l}\mathrm{EH} \\
(\mathrm{m})\end{array}$ & $\begin{array}{l}\text { PH } \\
(\mathrm{m})\end{array}$ & $\begin{array}{c}\mathrm{EL} \\
(\mathrm{cm})\end{array}$ & $\begin{array}{c}\mathrm{ED} \\
(\mathrm{cm})\end{array}$ & $\begin{array}{l}\text { EW } \\
(\mathrm{g})\end{array}$ & $\begin{array}{l}\text { EAD } \\
(\mathrm{cm})\end{array}$ \\
\hline Mo17 & 23.48 & 82.66 & 194.93 & 60.06 & 91.00 & 95.75 & 4.75 & 0.86 & 2.13 & 11.73 & 3.69 & 71.22 & 2.56 \\
\hline Huangzao4 & 27.85 & 81.84 & 193.30 & 46.62 & 88.83 & 93.00 & 4.17 & 0.69 & 1.79 & 10.66 & 4.02 & 56.43 & 2.84 \\
\hline
\end{tabular}

$\mathrm{KW}=100$-kernel weight; $\mathrm{KR}=$ kernel rate; $\mathrm{KTW}=$ kernel test weight; $\mathrm{EGW}=$ ear kernel weight; DPS = days to pollen shed; DS = days to silking; IPS = the interval between days to pollen shed and days to silking; EH $=$ ear height; $\mathrm{PH}=$ plant height; $\mathrm{EL}=$ ear length; $\mathrm{ED}=$ ear diameter; $\mathrm{EW}=$ ear weight; $\mathrm{EAD}=$ ear axis diameter.

Table 2. Descriptive statistics on 13 agronomic traits for the population derived from Mo17 x Huangzao4.

\begin{tabular}{|c|c|c|c|c|c|c|}
\hline Traits & Mean & Skewness & Kurtosis & Minimum & Maximum & $\operatorname{CoV}(\%)$ \\
\hline $\mathrm{ED}(\mathrm{cm})$ & 3.87 & -0.06 & 0.92 & 2.87 & 5.09 & 8.79 \\
\hline $\mathrm{EL}(\mathrm{cm})$ & 13.07 & 0.18 & 0.20 & 6.03 & 19.36 & 17.75 \\
\hline $\mathrm{EAD}(\mathrm{cm})$ & 2.75 & 0.30 & 1.41 & 1.95 & 3.66 & 9.09 \\
\hline EW (g) & 71.49 & 0.45 & 0.16 & 12.40 & 166.93 & 31.71 \\
\hline $\mathrm{PH}(\mathrm{m})$ & 1.94 & 0.32 & 0.61 & 1.39 & 2.76 & 11.65 \\
\hline $\mathrm{EH}(\mathrm{m})$ & 0.71 & 0.53 & 0.56 & 0.40 & 1.25 & 21.35 \\
\hline DPS (d) & 92.53 & 0.13 & -0.43 & 85.17 & 100.17 & 3.49 \\
\hline DS (d) & 98.27 & -0.03 & 0.00 & 88.67 & 106.25 & 3.25 \\
\hline IPS (d) & 5.80 & 0.57 & 1.07 & 0.83 & 14.75 & 36.38 \\
\hline KW (g) & 25.21 & 2.86 & 9.98 & 10.90 & 69.48 & 33.84 \\
\hline KTW (g) & 194.35 & -0.50 & 0.18 & 167.45 & 215.40 & 4.55 \\
\hline EGW (g/L) & 58.85 & 0.23 & 0.99 & 11.60 & 128.74 & 33.20 \\
\hline $\mathrm{KR}(\%)$ & 80.57 & -2.44 & 11.62 & 34.41 & 98.43 & 9.06 \\
\hline
\end{tabular}

$\mathrm{CoV}=$ coefficient of variation; $\mathrm{ED}=$ ear diameter; $\mathrm{EL}=$ ear length; $\mathrm{EAD}=$ ear axis diameter; $\mathrm{EW}=$ ear weight; $\mathrm{PH}=$ plant height; $\mathrm{EH}=$ ear height; DPS = days to pollen shed; DS = days to silking; IPS = the interval between DPS and DS; KW = 100-kernel weight; KTW = kernel test weight; EGW = ear kernel weight; KR = kernel rate.

\section{Correlation analysis of the population}

Correlation analysis was carried out among the 13 traits for the experimental popula- 
tion, and the results are listed in Table 3. The correlation between different agronomic traits could be classified into 5 types among the 78 correlation combinations: 0.01 level-positive correlation, 0.05 level-positive correlation, 0.01 level-negative correlation, 0.05 level-negative correlation, and no correlation (Table 4). Their statistic values were 28, 3, 11, 1, and 35, respectively.

Table 3. Correlation analysis between different traits for the population derived from Mo17 x Huangzao4.

\begin{tabular}{|c|c|c|c|c|c|c|c|c|c|c|c|c|}
\hline Traits & $\mathrm{KR}$ & KTW & EGW & DPS & DS & IPS & $\mathrm{EH}$ & PH & EL & ED & EW & EAD \\
\hline$\overline{\mathrm{KW}}$ & 0.052 & $0.205^{* *}$ & $0.158^{*}$ & -0.007 & -0.036 & -0.036 & 0.105 & 0.086 & $0.207 * *$ & 0.096 & $0.152 *$ & 0.096 \\
\hline KR & & 0.091 & $0.547 * *$ & $-0.219 * *$ & $-0.463 * *$ & $-0.341 * *$ & -0.038 & -0.016 & $0.233 * *$ & $0.304 * *$ & $0.434 * *$ & 0.04 \\
\hline KTW & & & 0.057 & 0.002 & 0.044 & 0.041 & 0.074 & -0.001 & -0.043 & -0.096 & 0.044 & 0.039 \\
\hline EGW & & & & -0.064 & $-0.298 * *$ & $-0.348 * *$ & $0.278 * *$ & $0.268 * *$ & $0.688 * *$ & $0.511^{* *}$ & $0.980 * *$ & $0.296^{* *}$ \\
\hline DPS & & & & & $0.785^{* *}$ & $-0.268^{* *}$ & $0.523 * *$ & $0.346^{* *}$ & -0.042 & -0.082 & -0.034 & -0.032 \\
\hline DS & & & & & & $0.363 * *$ & $0.336 * *$ & $0.242 * *$ & -0.128 & $-0.256 * *$ & $-0.250 * *$ & -0.057 \\
\hline IPS & & & & & & & $-0.283 * *$ & $-0.163 *$ & -0.124 & $-0.232 * *$ & $-0.322 * *$ & -0.038 \\
\hline $\mathrm{EH}$ & & & & & & & & $0.740 * *$ & $0.256 * *$ & 0.058 & $0.305 * *$ & 0.092 \\
\hline $\mathrm{PH}$ & & & & & & & & & $0.254 * *$ & 0.067 & $0.285^{* *}$ & 0.039 \\
\hline EL & & & & & & & & & & $0.212^{* *}$ & $0.711 * *$ & $0.153^{*}$ \\
\hline ED & & & & & & & & & & & $0.521 * *$ & $0.561 * *$ \\
\hline EW & & & & & & & & & & & & $0.336^{* *}$ \\
\hline
\end{tabular}

$\mathrm{KW}=100$-kernel weight; $\mathrm{KR}=$ kernel rate; $\mathrm{KTW}=$ kernel test weight; $\mathrm{EGW}=$ ear kernel weight; $\mathrm{DPS}=$ days to pollen shed; DS = days to silking; IPS = the interval between DPS and DS; EH = ear height; PH = plant height; EL = ear length; $\mathrm{ED}=$ ear diameter; $\mathrm{EW}=$ ear weight; $\mathrm{EAD}=$ ear axis diameter. ${ }^{*}$ Correlation significant at the 0.01 level (two-tailed). *Correlation significant at the 0.05 level (two-tailed).

\begin{tabular}{lcr} 
Table 4. Statistical values of different correlation types among the 13 agronomic traits. & No. \\
\hline Correlation types & Significant levels & 28 \\
\hline Positive & $0.01\left(^{* *}\right)$ & 3 \\
& $0.05\left(^{*}\right)$ & 11 \\
Negative & $0.01\left(^{* *}\right)$ & 1 \\
& $0.05\left(^{*}\right)$ & 35 \\
No correlation & & 78 \\
Sum
\end{tabular}

**Correlation significant at the 0.01 level (two-tailed). *Correlation significant at the 0.05 level (two-tailed).

\section{CONCLUSIONS}

In this study, 13 agronomic traits were investigated in an RIL population that was derived from Mo17 x Huangzao4 and its parents. According to the values of descriptive statistics of the parents and population and correlation analysis among the 13 traits in the population, it was concluded that these traits were quantitative and were controlled by multiple genes. The obtained data here could be further used for the QTL mapping of these traits in maize.

\section{ACKNOWLEDGMENTS}

Research supported by the Major Project for Genetically Modified Organisms Breeding from China Agriculture Ministry, P.R. China (\#2011ZX08003-001) and the Project for the Doctoral Research Program from Shanxi Academy of Agricultural Sciences, P.R. China (\#YBSJJ1106). 


\section{REFERENCES}

Bouchez A, Hospital F, Causse M, Gallais A, et al. (2002). Marker-assisted introgression of favorable alleles at quantitative trait loci between maize elite lines. Genetics 162: 1945-1959.

Ding JQ, Wang XM, Chander S and Li JS (2008). Identification of QTL for maize resistance to common smut by using recombinant inbred lines developed from the Chinese hybrid Yuyu22. J. Appl. Genet. 49: 147-154.

Fu S, Zhan Y, Zhi H, Gai J, et al. (2006). Mapping of SMV resistance gene Rsc-7 by SSR markers in soybean. Genetica 128: 63-69.

Guo JF, Su GQ, Zhang JP and Wang GY (2008). Genetic analysis and QTL mapping of maize yield and associate agronomic traits under semiarid land condition. Afr. J. Biotechnol. 7: 1829-1838.

Liu XH, Zheng ZP, Tan ZB and Li Z (2010). QTL mapping for controlling anthesis-silking interval based on RIL population in maize. Afr. J. Biotechnol. 9: 950-955.

Ma Z, Zhao D, Zhang C, Zhang Z, et al. (2007). Molecular genetic analysis of five spike-related traits in wheat using RIL and immortalized F2 populations. Mol. Genet. Genomics 277: 31-42.

Ordas B, Malvar RA and Hill WG (2008). Genetic variation and quantitative trait loci associated with developmental stability and the environmental correlation between traits in maize. Genet. Res. 90: 385-395.

Pilet ML, Duplan G, Archipiano M, Barret P, et al. (2001). Stability of QTL for field resistance to blackleg across two genetic backgrounds in oilseed rape. Crop Sci. 41: 197-205.

Ribaut JM, Jiang C, Gonzalez-de-Leon D, Edmeades GO, et al. (1997). Identification of quantitative trait loci under drought trait loci for yield component traits in maize by SSR markers. Acta Genet. Sin. 28: 778-784.

Wan X, Weng J, Zhai H, Wang J, et al. (2008). Quantitative trait loci (QTL) analysis for rice grain width and fine mapping of an identified QTL allele gw-5 in a recombination hotspot region on chromosome 5. Genetics 179: 2239-2252.

Wan XY, Wan JM, Jiang L, Wang JK, et al. (2006). QTL analysis for rice grain length and fine mapping of an identified QTL with stable and major effects. Theor. Appl. Genet. 112: 1258-1270. 